\title{
Vitamin A and carotene in British and American diets
}

\author{
By J. P. GREAVES AND JANE TAN \\ Ministry of Agriculture, Fisheries and Food, \\ Great Westminster House, Horseferry Road, London, SWI
}

(Received 4 March г966-Accepted 20 May 1966)

\begin{abstract}
1. The confusion sometimes found in discussions of dietary vitamin $A$ and its precursors is illustrated. The relative potency of vitamin $\mathrm{A}$ and carotene is briefly discussed, and the procedure used in the National Food Survey of Great Britain explained. 2. Changes in the vitamin $A$ and carotene contents of the British diet over the last two decades are illustrated. 3. The vitamin $A$ and carotene contents of the American diet are estimated, and compared with those of the British diets; both estimates of intake are compared with recommended allowances. The difficulties of making such comparisons are discussed, in view of the different conventions used in the two countries. 4. An appendix, on the calculation of vitamin $A$ in the diet, is included, in which interrelations between different methods of expressing vitamin A value are shown.
\end{abstract}

Discussion of dietary vitamin A and its precursors is sometimes confused because of the existence of three different ways in which quantities may be expressed: weight, international units (i.u.), and 'activity' or 'potency' (itself expressed in i.u.). Thus, the Committee on Nutrition of the British Medical Association (1950) state (p. 17) that a (British) 'mixed diet' contains one-third of its vitamin A as such and two-thirds as the provitamin, carotene, whereas Thompson (1965) and Plack (1965) estimate that a third 'of the total vitamin A intake' from the recent British diet is provided as carotene.

By internationally accepted definition (World Health Organization, I949, I950), I i.u. of vitamin A is equivalent to $0.3 \mu \mathrm{g}$ of vitamin $A$ alcohol and I i.u. of provitamin $\mathrm{A}$ is equivalent to $0.6 \mu \mathrm{g}$ of $\beta$-carotene, these quantities having an equal effect at the low levels of intake used in a specific rat assay. At higher levels of intake, carotene is less well utilized both in rat and man, so that in human nutrition these two quantities have a different effect, and thus the notion of international units, which is useful for grouping unlike things with like properties, is by current definitions not very helpful.

Though there may be a more or less fixed 'biochemical conversion factor' between carotene and vitamin $\mathrm{A}$, which has been assumed to be 2 in formulating the international definitions quoted above, there certainly is a highly variable 'nutritional conversion factor', which depends on species, the form in which the carotene is ingested, and the amount of carotene ingested. In the wartime Sheffield experiment reported by Hume \& Krebs (1949) it was found that men were less efficient than rats in utilizing carotene, and further that the absorption of carotene from different sources varied greatly; a compromise 'nutritional conversion factor' of 3 was finally chosen, so making vitamin A six times more active (on a weight basis) in man than carotene as derived from an ordinary mixed diet. For cattle under natural conditions the sole source of vitamin $\mathrm{A}$ is carotene, and most of the evidence points to carotene 
having, on a weight basis, one-fifth of the activity of vitamin A (S. Y. Thompson, personal communication).

On the evidence of the Sheffield experiment, the Medical Research Council (1945; and see McCance \& Widdowson, I960, p. I63) recommended that to obtain an approximate value for the total vitamin $A$ potency of a mixed diet the total carotene in i.u. should be divided by 3 and added to the value for total preformed vitamin $A$. This is essentially the practice adopted in the National Food Survey, for which the divisor 3 is incorporated into the conversion factors for vitamin A for appropriate food groups, and thus all National Food Survey figures are in terms of vitamin A potency, as pointed out, for example, by Hollingsworth (I965). In the United States, however, a different practice is usually adopted (see below).

In considering requirements for vitamin A, the British Medical Association (1950), also following the results of the Sheffield experiment, considered that carotene is less well utilized than vitamin A to the extent of one-third (in terms of i.u.), but in the United States a factor of one-half is assumed: 'for practical purposes it is considered that 2 i.u. of $\beta$-carotene are equivalent to $\mathrm{I}$ i.u. of vitamin A in man' ((USA) National Research Council, I964, p. 20).

When comparing one survey with another it is therefore important to know how the vitamin A values are expressed: the interrelations between different methods are expressed algebraically in the appendix to this paper. The resolution of the paradox posed in the first paragraph of the present paper is that the British Medical Association ratios were in terms of international units, whereas those of the later authors were in terms of potency (see Fig. I).

\section{Vitamin $A$ and carotene in the British diet}

Hollingsworth (1965) has discussed the trend, as revealed by the National Food Survey, in the sources of vitamin A in the British diet over the two decades I942-62. Mean daily consumption has increased from about 3000 i.u. (vitamin A potency) per head for the years $1942-9$ to about $4300-4400$ i.u. for 1956 and subsequently; this increase was shown by Leitner, Moore \& Sharman (1960) to be reflected in an increase in the vitamin $A$ in the blood of both men and women. Over this period the percentage contribution from vegetables containing carotene dropped from more than one-third of the total in $\mathrm{I} 942$ to about one-fifth, while the contribution from animal sources containing the preformed vitamin increased. There has thus been an obvious change in the relative proportions of preformed vitamin and precursor in the total vitamin $A$ potency of the diet; these proportions are illustrated in Fig. I. The proportions were calculated from the known contribution of different foods to the total vitamin A potency, allowance being made for the presence of carotene in milk, cream, cheese, butter and eggs. In terms of international units, preformed vitamin A accounted, during the war years, for about $30 \%$ of the total, and latterly rather nearer $40 \%$; in terms of potency, or equivalent vitamin A activity, for about $56 \%$ during the war years, and latterly about $65 \%$, carotene providing respectively about $44 \%$ and $35 \%$.

A rather more sophisticated analysis, calculated from weights of vitamin $A$ and carotene, is given in Table $\mathbf{I}$. 


\section{Vitamin $A$ and carotene in the American diet}

The hazards of comparing the results of one survey with those of another are many. Thompson (1965) compared an estimated intake of 4306 i.u. vitamin A per day, from the National Food Survey of Great Britain for 1962, with an estimate of 10155 i.u.
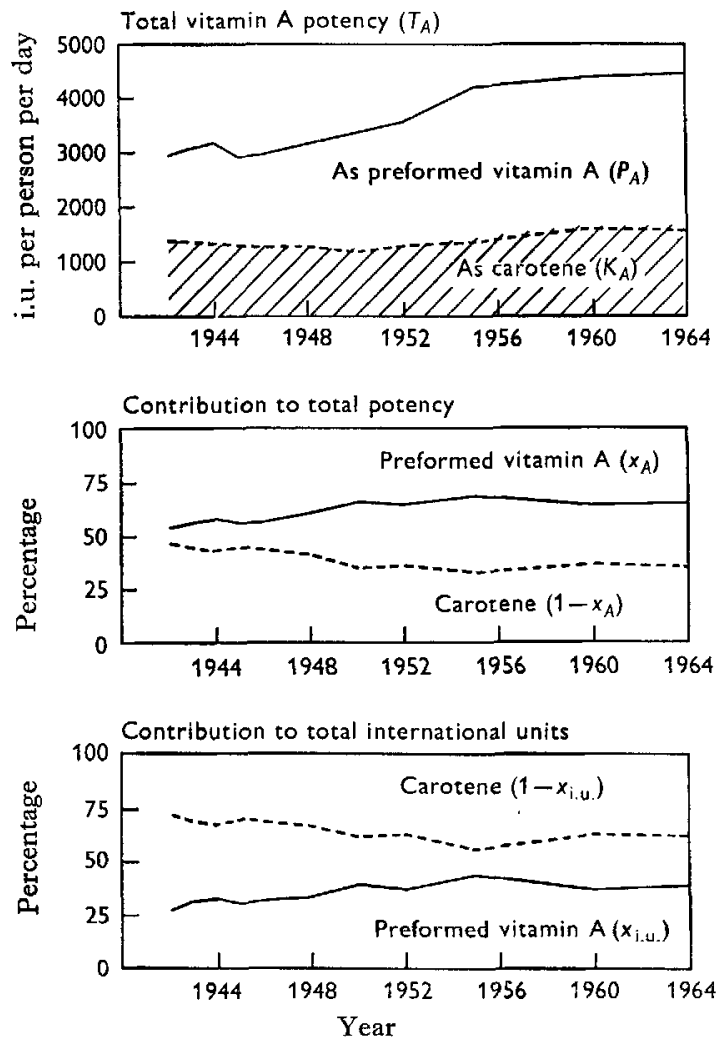

Fig. I. Vitamin A and carotene in the British diet. Results of the National Food Survey: 1942-9, urban working class households; 1950-64, all households. Algebraic symbols are discussed in the appendix.

Table I. Results of the National Food Survey for all households for 1964

Total vitamin $\mathrm{A}$ and carotene in terms of:
Percentage of total contributed by

Preformed vitamin A Carotene

from the United States Household Food Consumption Survey for 1955, concluding that, in the United States, 'the total vitamin A intake (I0200 i.u. daily) is two and a half times that in Great Britain'. 'This conclusion is unwarranted for several reasons, with which Thompson, after consultation, fully agrees.

In the first place the American estimate quoted is not representative of the full 
sample, in that the farm households have been excluded: the national figure is 9957 i.u. (about 9960 i.u.) (United States Department of Agriculture, 1957). In the second place these estimates are per 'nutrition unit' (or equivalent young adult male), whereas the British results are expressed on a per person basis; the appropriate American per person figure is $854^{\circ} \mathrm{i}$.u. (The complications arising from the fact that a 'person' is defined, for survey purposes, differently in the two surveys are not considered here.) Thirdly, and most importantly from a quantitative point of view, the American figures for 'vitamin A value' are in terms of total international units ('no allowance has been made... for differences in availability of the precursors as sources of vitamin A value from different types of food' (Watt $\&$ Merrill, 1963, p. 167), whereas the British figures, as has been stated above, are in terms of potency.

From a knowledge of the contribution of the different food groups to the total intake of 9957 i.u. per nutrition unit (United States Department of Agriculture, 1957, Table 5) it is possible to estimate that 4087 i.u. came from preformed vitamin A and 5870 i.u. came from carotene. If a divisor of 3 is applied to the carotene units-as in Britain - the vitamin A potency of the diet comes to 6044 i.u. per nutrition unit, or (from the values in Table $\mathrm{I}$ of the reference quoted immediately above) about $5_{1} 80$ i.u. per person. This is the figure which can be more properly compared with British figures, and is some $20 \%$, markedly less than Thompson's estimate of nearly $150 \%$, above the estimated British intake quoted by him.

\section{Comparison of estimated intake with recommended allowances}

Because the National Food Survey results are given as preformed vitamin A, or vitamin A potency, they are properly compared with the British Medical Association's (1950) recommended allowances in the same units; for example, the daily allowance for an adult is taken as 2500 i.u., and any assumption about the relative contributions of vitamin A and carotene to the total intake is obviated. The vitamin A potency of the average daily household food consumption in Great Britain in 1962 was about 43 ro i.u. per person, estimated as $185 \%$ of the recommended allowance (Ministry of Agriculture, Fisheries and Food: National Food Survey Committee, 1964). In calculating this percentage a conventional deduction of 10\% was made for non-ingestion of food, and allowances were made for meals served to visitors and for meals consumed outside the home (as described in Appendix $G$ of the reference quoted immediately above, and in appropriate appendices of later annual reports of the National Food Survey Committee).

In the United States, the custom is to compare consumption in terms of nutrition units with the allowance for an adult male. Thus, in the example used above, the figure 9960 i.u. for vitamin A value is compared with an allowance of 5000 i.u. (United States Department of Agriculture, I96r, p. 9). However, the value of 5000 i.u., appropriate for a 'mixed diet', implies that one-third of the vitamin A activity is supplied by the preformed vitamin, since the equivalent allowance in terms of preformed vitamin A is 3000 i.u. ((USA) National Research Council, 1964 and earlier editions). However, if the estimates derived above for the amounts of preformed vitamin A and carotene in the American diet are correct, the proportion of vitamin A 
activity supplied by the preformed vitamin is in fact $4087 \div\left(4087+\frac{1}{2} \times 5870\right)$, or about $58 \%$. If this proportion is accepted, rather than the assumed one-third, and if an allowance of 3000 i.u. in terms of preformed vitamin $A$ is also accepted, then it can be shown that the allowance in terms of international units for a mixed diet of such proportions is 4260 i.u., rather than 5000 i.u. (see appendix, equation 8 ). The consumption figure of 9960 i.u.-less $10 \%$-is $210 \%$ of the derived allowance of 4260 i.u., which is about $14 \%$ above the roughly equivalent British percentage of 185 .

If the American data are considered in terms of preformed vitamin A a (necessarily) similar result is obtained. On the assumption that 2 i.u. carotene $=\mathrm{I}$ i.u. vitamin $\mathrm{A}$, the total vitamin A potency of the diet is 7022 i.u. $\left(4087+\frac{1}{2} \times 587\right.$ i.u.) per nutrition unit, to be compared with an allowance of 3000 i.u. Again with $10 \%$ allowed for wastage, the allowance is exceeded by $210 \%$.

Finally it is hoped that the joint WHO/FAO Expert group which met towards the end of 1965 to consider requirements for vitamin A will have resolved some of these complications-perhaps by abandoning the use of international units-but in the meantime caution is advisable, and it is hoped that this paper, with its accompanying appendix, may assist in the manipulation of units, and explain the procedure used in the National Food Survey of Great Britain, as well as illustrating some changes that have occurred in the British diet over the last two decades.

We acknowledge with gratitude the advice and encouragement we have received from Dr T. Moore and Dr S. Y. Thompson.

\section{REFERENCES}

British Medical Association (1950). Report of the Committee on Nutrition. London: British Medical Association.

Hollingsworth, D. F. (1965). Nutrition, Lond. 19, 6.

Hume, E. M. \& Krebs, H. A. (1949). Spec. Rep. Ser. med. Res. Coun. no. 264.

Leitner, Z. A., Moore, 'T. \& Sharman, I. M. (1960). Br. F. Nutr. 14, I 57.

McCance, R. A. \& Widdowson, E. M. (1960). Spec. Rep. Ser. med. Res. Coun. no. 297.

Medical Research Council (1945). Med. Res. Coun. War Memo. no. 14.

Ministry of Agriculture, Fisheries and Food: National Food Survey Committee (1964). Domestic Food Consumption and Expenditure: 1962. London: H.M. Stationery Office.

National Research Council (1964). Publs natn. Res. Coun., Wash. no. I I46.

Plack, P. A. (1965). Proc. Nutr. Soc. 24, 146.

Thompson, S. Y. (1965). Proc. Nutr. Soc. 24, 136.

United States Department of Agriculture (1957). Household Food Consumption Survey 1955. Report no. 6. Washington: US Government Printing Office.

United States Department of Agriculture (196r). Household Food Consumption Survey 1955. Report no. I6. Washington: US Government Printing Office.

Watt, B. K. \& Merrill, A. L. (1963). Agric. Hdbk agric. Res. Serv. no. 8. Washington: US Government Printing Office.

World Health Organization (1949). WHO Chron. 3, I47.

World Health Organization (1950). Tech. Rep. Ser. Wld Hlth Org. no. 3.

\section{APPENDIX}

On the calculation of vitamin $A$ in the diet

(I) Let preformed vitamin $\mathrm{A}=P$, carotene (assumed to be, or to be equivalent to, $\beta)=K$, total vitamin A plus carotene $=T$, overall efficiency of utilization of $K$ $=e$, fraction of $P$ in $T=x$. Quantities may be expressed in three different units: 
weight, international units, or international units modified to represent 'equivalent vitamin A activity' or 'potency'.

Let quantities expressed by weight be denoted by suffix $\mu \mathrm{g}$, quantities expressed in international units (unmodified) be denoted by suffix i.u., quantities expressed in terms of vitamin A potency, be denoted by suffix $A$.

By definition $P_{A}=P_{\text {i.u. }} ; K_{A}=e K_{\text {i.u. }} ; P_{\text {i.u. }} \times 0.3=P_{\mu \mathrm{g}} ; K_{1 . u \text {. }} \times 0.6=K_{\mu \mathrm{g}}$.

There are three possible definitions of $x$, depending on the units employed, namely

Therefore

$$
x_{\mu \mathrm{g}}=\frac{P_{\mu \mathrm{g}}}{T_{\mu \mathrm{g}}}, \quad x_{1 . \mathrm{u} .}=\frac{P_{\mathrm{li \textrm {u }} .}}{T_{1 . \mathrm{u} .}}, \quad x_{A}=\frac{P_{A}}{T_{A}} .
$$

$$
\begin{aligned}
T_{\mu \mathrm{g}} & =P_{\mu \mathrm{g}}+K_{\mu \mathrm{g},} \\
T_{\text {i.u. }} & =P_{\text {i.u. }}+K_{\text {i.u. }}, \\
T_{A} & =P_{A}+K_{A}, \\
& =P_{\text {i.u. }}+e K_{\text {i.u. }}, \\
& =\frac{P_{\mu \mathrm{g}}}{0.3}+\frac{e K_{\mu \mathrm{g}}}{0.6} .
\end{aligned}
$$

(2) The British and American assumptions, as discussed in the text, can be expressed as follows: UK assumptions: $e=\frac{1}{3}, x_{1 . u}=\frac{1}{3}$; USA assumptions: $e=\frac{1}{2}, x_{A}=\frac{1}{3}$.

It should be noted: (a) $x_{A}$ is related to $e$, as follows:

$$
x_{A}=\frac{P_{\text {i.u. }}}{P_{\text {i.u. }}+e K_{\text {i.u. }}} ;
$$

$x_{\text {i.u. }}$ is independent of $e$, and is to this extent a better measure.

(b) The USA assumptions above are equivalent to an assumed value of $x_{1 . u .}=\frac{1}{5}$, as may be seen by substituting into the equation

$$
x_{\text {i.u. }}=\frac{e x_{A}}{\mathrm{I}-x_{A}(\mathrm{I}-e)} \text {. }
$$

(3) These relationships may be used to convert 'requirements' from one basis to another. For example, if requirements are given in terms of total international units of vitamin and provitamin in a mixed diet, what would requirements be in terms of preformed vitamin A only? In other words, given $T_{\mathrm{i} \text {.u. }}$, what is $T_{A}$ ?

The solution depends on both $e$ and $x$, and there are two expressions, to take account of the two ways in which $x$ might be defined:

$$
\begin{aligned}
T_{A}= & T_{\text {i.u. }}\left(\frac{\mathrm{I}}{x_{A}+(\mathrm{I} / e)\left(\mathrm{I}-x_{A}\right)}\right) \\
\text { or } \quad & T_{\text {t.u. }}\left(x_{\text {1.u. }}+e\left(\mathrm{I}-x_{1 . u .}\right)\right) ;
\end{aligned}
$$

e.g. (a) if $x_{A}=\frac{1}{3}, e=\frac{1}{2}$ (USA assumptions) then from equation (8) $T_{A}=0.6 T_{\text {i.u. }}$; therefore, if $T_{\text {i.u. }}=5000, T_{A}=3000$, etc.

Alternatively, equation (9) could be used to recalculate requirements on the USA scale, if the value of $x_{\text {i.u. }}=\frac{1}{5}$ (derived from equation (7)) is used.

(b) If $x_{\text {i.u. }}=\frac{1}{3}, e=\frac{1}{3}$ (UK assumptions) then from equation (9) $T_{A}=\frac{5}{9} T_{1 . \mathrm{u}}$; therefore, if $T_{\text {i.u. }}=5000, T_{A}=2778$ i.u., etc. 